\title{
The Role of Mass Media In Smoking Problenf Children
}

By David Nostbakken

Television is probably the most "mass" of the
mass media. People don't just "watch" mass media. People don't just "watch"
television, they live with it. It is how we "see", not just learm, what is going on in the "see", not just learn, what is going on in the
world, how people live, how they look, walk,
talk and dress. Paula Green, 1979 INTRODUCTION

This article, in examining the role of children, will focus discussion on the place of television. It is recognized that mass media alone, and television in particular, represent one element among
several in a comprehensive nonsmoking program. Legislation efforts, educational program, cessation programs, group and a full comprehensive approach. It is difficult to measure the immediate impact of television, film or other mass media
alone, apart from other components of alone, apart from other components of
the smoking control program. The the smoking control program. The
research available on the subject is sparse
and, as shall be seen, somewhat underdeveloped.

Film will be included in this article only inasmuch as television lends itself to the
use of film. Of course, films can be used in group settings or in a classroom apart from the television reach. As will be seen, however, the use of film in this settin has a different purpose and value than film used on televison. Both uses of film are important in a comprehensive nonof television programming throughout, it is meant to include nonsmoking films shown on television.
I will begin with a brief note on the smoking problems of children. This is of television in influencing the performance of children and youth with special reference to nonsmoking. Then, the utili-
ty of television in supporting nonsmokers to remain nonsmokers is examined. This is followed by a discussion of the strength its content, viewing patterns and the viewing context for supporting and crystalizing nonsmoking attitudes and beliefs. Finally, recommendations are offered on the use of
television for nonsmoking, and exaraples television for nonsmoking, and
of its use in the past are given.

David Nostbakken is the director of Public Education, for
Cancer Society in Toronto.
SMOKING PROBLEMS OF CHILDREN

It is well recognized that reasons for for continuing to smoke. The developleading to adulthood influence the propen-
sity to smoke or not to smoke. In this sity to smoke or not to smoke. In this
section, a number of assumptions will be made that may be expressed as follows:

- Children begin modelling significant others (parents, heroes, friends, authority figures) within the first year of life. Smoking parents and other exemplars begin inlong before the child is conscious of the influence.

- By the age of 6 to 12 , children, out of curiosity, peer pressure, the desire to experience and emulate, begin to conscious mplars, including those friends and in

- By adolescence, the spirit of independence, particularly from parents
and authority figures, often leads to conformity with the peer group or other strong examples in the life of the constraints. Where the peer group, for
example, is smoking, the influence is Clearly, children do not begin to smoke because of a well-articulated and undertood rationale or logical argument for pers to ditions, needs, desires and curiosities interrelate with strong and pesuasive exemplars and their environment.

There are more children not smokin han there are smoking. Prevention children and youth. It is an assumption here that emphasis should be placed on supporting nonsmoking youth to remain nonsmokers for their own well-being an perimenting with smoking or are smokperimenting with smoking or are smokexample, for children and young peple who do not smoke to remain o support and to encourage nonsmokers never to begin or want to begin smoking. 1A thorough discussion of the developing
child and smoking problems can be found in a child and smoking problems can be found in a
presentation by Dr. Bob Wake recorded in the Proceedings of the 4th World Conference on
Smoking and Health entitled The Smoking
Epidemic (1979).
THE ROLE OF TELEVISION IN CHILDREN: A QUESTION OF PERFORMANCE

To determine the role of television in the smoking problems of children, it is television in the lives of childre generally.

A broad review of the literature on the sense in which children pay attention to television, comprehend what they see
and hear, how children retain the subje matter of television, and just how they in teract with television and its programm ing. Here, however, the sense in which the child will be the centre of discussion for ultimately, with respect to smoking,
that is what counts. "Performance" refers to the display in real life of acquire ther verbal or behavioura. necessary condition for performance mation, attitudes and valye systems. A quisition can only be measured by some sort of performance. In practical terms
all the variables that affect acquisitio also affect performance. tion and performance must be considered separately. She argues that a child ma learn parental behaviour by observing his not be perform a parent. Put differently, acquired responses may not occur until the person encounters eliciting conditions, or roles
(Bandura, 1965 to 1969,1971: Bandura (Bandura, 1965 to 1969, 1971; Ba
and Walters, 1963; Mischel, 1968).

and Walters, 1963; Mischel, 1968).
What one perceives as the alternative available in a given situation influence there are not alternatives, or only a few the likelihood of display will be affected
by the acquistion of new alternatives. by the acquistion of new alternatives.
Once past early childhood, most humans have acquired a repertoire of responses that may be displayed in a given situation on a number of additional factors. A good deal of behaviour, contends
Bandura (1971), is cognitively mediated Bandura (1971), is cognitively mediated
and controlled by anticipated consequences of actions. Young children, against peers than against parents
because they accept different consequences for perfoming the same behav iour (Bandura and Walters, 1959). Th
behaviour is governed by the subjectiv VOLUME 13, NUMBER 2, 198 perceptions of the person, the objective
circumstances and on the basis of information acquired previously. In other
words, behaviour here is influenced by he individual's "image" of his world o cial reality. This "image" includes all hose things that constitute the social norms and exp

Performance, then, is a function of at Past two face, then, is a fitions and conife situation, and the child's individu cognitions or perceptions about those
onditions and contingencies. For example, the presence of a teacher may sharply will smoke in the school hall a teenage ver, a teenager's perception of cigaret-
es, teachers and school will influence the robability of performance. The teenager out of punishment, or who expects prais out of punishment, or who expects prais
from his peers for his actions, is more likely to smoke in the hallway than someone

Television may have minimal influen on social behaviour to the extent that perconditions. Incentives and conditions in the social environment are not under the on can influence social behaviour he extent that it influences the norm
and expectations that a child brings to he behavioural situation. Many psybologists agree that children's defident on socially-mediated informatio and several have pointed out that mass media are important sources of such in-
formation (Bandura, 1969; R.Brown, 965; E.E. Jones and Gerard, 1967; hoberts, 1973). Television's influence o each new behaviour, and also in its co tribution to the young person's definition propriate behaviour and what constitutes e situational and behavioural contingencies which should control perfor-
mance (Leifer and Roberts, 1972). For exmple, to the extent that television congressive behaviour is frequently rewarded or that submissiveness is the appropriate behaviour for women, or that smoking is a common and acceptable practice, the medium can be expected to
influence behaviour (although not to known degree). This is not necessarily to
imply that television content is more im portant than other agents of socialization. It is generally accepted that television
most effectively influences the role of social behaviour either when it reinforces e attitudes, expectations and definitions romulgated by direct experience and terpersonal communication, or when it 列 B.S. Greenber, 1974; Klapper, 1960;

With the respect to children, perforthe related and environmentally-related facs that mediate acquisition. Some Tical examples follow.

ation about the likely conseques inforvarious actions, like smoking, for example, or about the conditions under which behaviour, like jogging, for example, can constitutes appropiate behaviour, such as nonsmoking in various situations, has been shown to affect the likelihood of children's performance of similar at when symbolic behaviour is explicitportrayed as rewarded or punished, behaviours on the part of children respectively increases and decreases (Bandura, 1965; Elliott and Vasta, 1970; Leifer and
Roberts, 1972). Further, performance is more likely to follow after viewing mply positive consequences. This is often influenced by models who are high in prestige, attract

Those behaviours shown on television and Rawlings, 1963: Collins, Berndt and Hess, 1974), to the extent that the

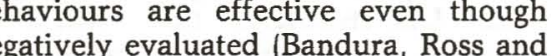
Ross, 1963; Zajonc, 1954), and to the exent that they are portrayed by role phropriate models (Hicks, 1965), or by
characters or within situations which children can easily identify because of perceived similarity, increase the performance of television-mediated behaviour. ateness of portrayed behaviours also ap pear to depend on the "reality" of the presentation. The more realistic or true-
to-life the content, the more likely viewing is to lead to subsequent performance Feshbach, 1972). quency and consistency with which cerchildren to perceive those behaviours as ppropriate, as reflections of society's or definitions of what to expect in

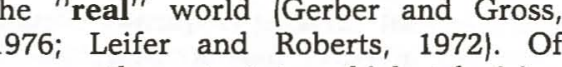
course, the extent to which television
content forms children's definitions of content forms children's definitions of
social reality is influenced by the same
child-related variables known to be factors in connection with the acquistion portrayed behaviours with portrayed conpquences, for example, or comprehend particular consequences as positive or portrayal as relistic, depends on such child-related characteristics as age and level of cognitive development, sex or personality. In short, the acquisition of pevision is and expectations from uisition of behaviour or ock, et al., 1978).

Clearly, then, television is only one of orms. Regardless of where young people however, the degree to which they con-
however Thus, while a child's inhibition of antimoking behaviour, like smoking, for example, may largely depend on some ejection, for another child the perford control, such as expectations of selfcondemnation or a feeling of guilt. Comstock, et al. (1978) point out that a o which social norms are internalized. One of the most important in the present cumulative process. The more experience the longer he has been exposed to definithe are both explicit and implicit of likely he is tocial behaviour, the more rules. It follows that the likelihood that internalized social norms will govern the vert performance of any behaviour is in Considering the re

between haviour and age, we are faced with the situation where younger children are less likely to learn complex behavioural sequences but more likely to perform the behaviours that they do learn because of 
children, who experience little difficulty acquining behaviours from television, are social norms. These norms have been defined by many other sources in addiparticularly critical if one considers the evidence that young children often comprehend and retain specific behaviours and actions portrayed on television, but not the conter perces surrounding them. and note that smoking frequently occurs. The child, however, may not comprehend the contingency surrounding such behaviour. By virtue of his age, he is also less likely to have internalized controls try out the observed behaviour of smoking at some time, if only in later life in the face of other conditions.

Berkowitz (1962) has argued that the more a situation is similar to that portrayed on television, such as the setting of in the setting the greater the likelihood that the child will display the behaviour portrayed on television. Berkowitz (1965) reports a series of studies showing that when elements that are similar to those portrayed on thevision are present in similar to that exhibited on television increases in the child. Subsequent performance of observed behaviour increases the more nearly the child's situation or setting matches that of the setting represented on television (Fland.

Comstock, et al. (1978) review how information provided directly to the young person by his environment also influences how he interprets and accepts
television information. When television provides information about social situations and norms which are unavailable to the person, from other sources or from direct experience, that information is likethe person encounters a situation similar to that portrayed on television. Way back that the attitudinal impact of movies dealing with various ethnic groups was greater with unsophisticated children or as opposed to a large heterogeneous urin 1958, Siegel revealed that the impact of radio programs on second-grade children who had little or no experience vrith taxi
drivers. B.S. Greenberg (1972) found that drivers. B.S. Greenberg (1972) found that grounds were more likely to say that they used television for information about $k \mathrm{c}, \mathrm{N}$ to behave with black people than their urban counterparts. Those in the urban setting, where blacks and wrhites work and
live together in a normal fashion reported less use of the medium for this (1966) found that when ehaviour was not easily found in the

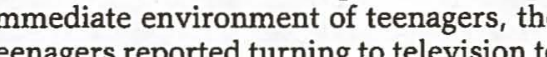
get that information. The importance of parental influence in documented. A body of literature no elated to the smoking problem or to and sanctions, as well as the manner in which these behaviours and sanctions ar communicated, significantly shape the expectations and behaviour of childre Baumrind, 1972; Maccoby and Jacklin, ndicating that comments made to children by adults while viewing a television program significantly affect the way the child interprets the program and the y perform behaviours acquired from the program (Prasad, Rao and Sheikh, 1978; dren who view Sesame Street in the presence of parents who discuss the program with them learn significantly more than the children who view it alon

In summary, the period between birth rapid change. In 20 years, experiences capabilities, all undergo developmenta changes, most of which have implications and the young person (Roberts, 1973). gainst which to judge new information b) qualitatively and quantitatively diferent cognitive capabilities and strategie by which new information is processed,
and (c) different physical capabilities for performing a behaviour. As a result, peak of how television influecnes "young persons" or "children", it is rapidly becoming apparent that in many fuences and is used by 4 year olds, 6 yeer olds, 10 year olds, and perhaps 14 year olds. Unfortunately, the wealth of iterature on children and television fails to deal in any major way with thes

TELEVISION FOR THE SUPPORT OF ANSMOKING AMONG CHILDREN

The foregoing discussion as it relates to Then an ant of change in the which it is an agent for socialization the fllowing figure:

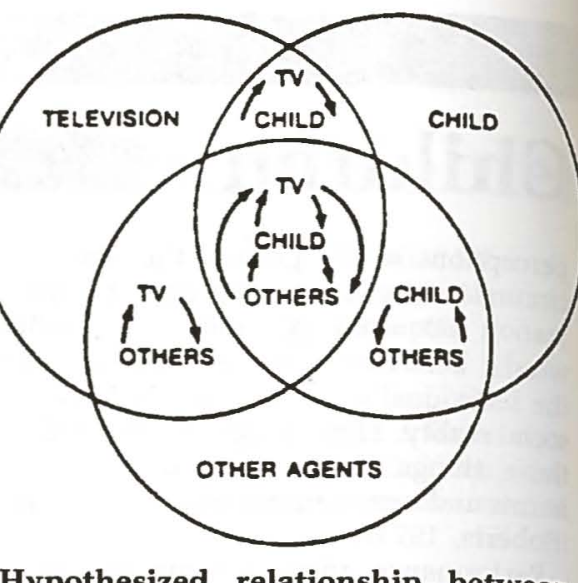

Hypothesized relationship between
television and other agents of socialization.

SOURCE: Adapted from A.D. Leifer, N.J. Gordon, and S.B. Graves, 1973. Children and Telev-
sion: Recommended Directions for Future Efforts Center for Research in Children's Television

In this figure, all influences on the behaviour and socialization of the child such as parents, peers and environment, have been collapsed into the segment
called "Other Agents". Also to be taken into account, of course, are socio-economic factors, levels of education,
literacy levels and social conditions. The figure emphasizes that socialization is a process of many interactions. The young television or others. Each may be in lenced multiple interactions among the child television and other agents is apparent. The effect of television on young people is result of such multiple interactions tha is as a direct influence.

In designing a program, therefore, to use television in support of nonsmoking television should be regarded as but one of several elements of the program for that mass media exercises an all-powpoin or hypodermic impact on receivers was popular in the 1930's and 1940's Lazarsfeld, Berelson and Gaudet, 1948 This notion soon fell out of favour, direct in, due to lack or evidence of the voters during elections. The ystematic scientific research studies after World War II led to pessimistic conclusions among several media specialist and funding agencies that media were im potent. Subsequent research recognized models of communication and change were insufficient (Schramm and Roberts, 1971). Examination of the direct influence of television on changing beliefs and attitudes and broader cognitive
behavioural trends were carried ou VOLUME 13, NUMBER 2, 1984
Becker, McCombs and McCloud, 1975; Blumler and McLeod, 1974; Kraus and
Davis, 1976; McCombs, 1972). In the Davis, field, Griffiths (1957) suggested bree basic steps necessary for bringin pot only on the use of mass media but on other social change efforts as well. The three steps were: (1) creating or changing
perceptions /beliefs, attitudes, values, perceptions leelings), (2) utilizing motivational forces, ree, he main hree, healistic attempt at changing or in-
for a realis HUMAN STATE

fluencing smoking behaviour. Fishbein (1977) describes "an empirically-based"
socio-psychological theory of the relationshps among beliefs, attitudes, intentions and behaviour that is consistent findings in the smoking literature. These spokesmen, and others, are clear that the ultimate goal of changing smoking behaviour can be achieved only in relation to changes in other human states
besides behaviour. The following figure illustrates what some of these human states and desired conditions are:

DESIRED CONDITION

\begin{tabular}{|c|c|}
\hline $\begin{array}{l}\text { PERCEPTIONS } \\
\text { - beliefs } \\
\text { - attitudes } \\
\text { - opinions }\end{array}$ & $\begin{array}{l}\text { - People are more attractive } \\
\text { when they don't smoke } \\
\text { - Most people don't smoke } \\
\text { - Smoking leads to poor health } \\
\text { - If I smoke I increase my } \\
\text { chances of getting cancer }\end{array}$ \\
\hline $\begin{array}{l}\text { INTENTIONS } \\
\text { - motivation } \\
\text { - enthusiasm } \\
\text { - commitment }\end{array}$ & $\begin{array}{l}\text { - Never begin smoking } \\
\text { - I will quit on Monday } \\
\text { - I will hang out with kids who } \\
\text { don't smoke }\end{array}$ \\
\hline BEHAVIOUR & $\begin{array}{l}\text { - Continued nonsmoking } \\
\text { - Stop smoking } \\
\text { - Throw out ashtrays } \\
\text { - Avoid smoking situations }\end{array}$ \\
\hline
\end{tabular}

Further, there is evidence that some change methods are more suited than others bringing about desired change:

TO BE CHANGED

MOST EFFECTIVE CHANGE
METHODS

\begin{tabular}{|l|l|}
\hline PERCEPTIONS & $\begin{array}{l}\text { Mass media methods (television, } \\
\text { radio, posters, billboards, pamphlets) }\end{array}$ \\
\hline INTENTIONS & $\begin{array}{l}\text { Group methods (family, classroom, } \\
\text { clubs, community programs, work- } \\
\text { shops, seminars, conferences, } \\
\text { business and workplace) }\end{array}$ \\
\hline BEHAVIOUR & $\begin{array}{l}\text { Personal decision and change } \\
\text { methods (individual, face-to-face, } \\
\text { e.g., parent-to-child, teacher-to- } \\
\text { student, doctor-to patient) }\end{array}$ \\
\hline
\end{tabular}

ANADIAN JOURNAL OF EDUCATIONAL COMMUNICATION
The strength of mass media is in supporting or crystalizing beliefs and at motivated by other people. Individualmotivated by other people. Individualecessary final touch for important the sions that lead to action and change (Escarpit, 1977; Atkin, 1978). This is not to say that one change method has exclusive jurisdiction over a Iven behaviour or pattern of change. It is
mportant, however, that expectations for the effectiveness of a given approach are not unrealistic in relation to probable outcomes. A strong mass media appeal for smoking control may yield disappointing missing telly or in part, interpersonal is settings or in one-to-one situations. However, beliefs, opinions and levels of awareness may be significantly changed or supported following mass media efforts. Group activities in the classroom, for example, and social movement insmoking in public places, may be supportive of nonsmoking in the short run but insufficient in the long haul if there is no mass media promotional support. One-toone situations, particularly among peers
or between individuals with mutual respect (husband and wife among adults, father and daughter, brother and sister| or in authority situations (doctor to young patient, teacher to student) are often at the root of major behavioural or lifestyle chanes methods mealily, the three thether supportively, and all three are
togethe necessary for a cogent, comprehensive smoking control program. It should be clear by now that a strong media program is not meant to take the place of personal contact through schools, community
groups, a doctor's office, or the home. groups, a doctor's office, or the home.
When the three approaches are combined in a supportive, nonsmoking climate, we maximize the potential for creating what has been called in the UICC manual Guidelines for Smoking Control .... a
living atmosphere of social rejection of
the smoking habit, an atmosphere where no one wants to smoke."

TELEVISION AS AN AGENT FOR SUPPORTING AND CRYSTALIZIN

Early in this Article, a number of assumptions regarding the "Smoking Problems of Youth" were expressed. In
sum, the assumptions point to the importance of providing appealing and popular examples for young people to imitate and model. The International Union Against
Cancer technical series, Vol. $73, A A$ Cancer technical series, Vol. 73 , A
Manual on Smoking and Children, states: Since more children do not smoke
than do, the highest priority for pre 

maintaining the nonsmokers as nond reward in all our educational stand firm, to become impervious ther inducements to smoke and in creasingly will be seen as popular

Given that mass media in general and television in particular for the purpose of
this discussion, have their strength in influencing perceptions (beliefs and at titudes) we shall see next how support
and strength for nonsmokers to remain nonsmokers is derived from television. First, a brief review is offered on the

The Medium

The medium of television is pervasive. one television, and $94 \%$ of Canadians use the set every day. The following table ilustrates the extent to which television permeates fres time in several countries: vention should be allocated to efforts. By so doing, the to peer pressure, curiosity and ey the coming nature of the television medium, its con-
tent, the viewer and the viewing context.

countries of the world. Health educators have an opportunity to integrate their
perceptions into the character of life for most children, on most days, where the
childen are in the privacy of their homes.

The Content

In most countries, and certainly in
North America, programming of all inds, from comedy, to drama, to variety, documentary and news, is designe tainment formulas, thus, become the structure of any content, message or imagery offered through the medium. There is a good deal of repetition throughou programs and commercials. The lliusion the in the present. Television, thus, affords through the illusion of movement, something for the viewer to deal with it in the present - an experience, an existential paced content, is an experiential mode that does not support "hard-core" factual information, statistics or the didactic approach. It provides, rather, appealin approach. It provides, rather, appealing
imagery, appealing identifiable without discussion, without being asked
characters and models and a feeling of to recall and never having to untangle the Television Usage and Free Time in 12 Nations for an Average Day (in 1965)

\begin{tabular}{|c|c|c|c|c|c|c|c|c|c|}
\hline \multirow[b]{2}{*}{ Sample Site } & \multirow[b]{2}{*}{$\begin{array}{l}\text { Percent Set } \\
\text { Ownership }\end{array}$} & \multirow[b]{2}{*}{$\begin{array}{l}\text { Percent That } \\
\text { Watched } \\
\text { Any TV }\end{array}$} & & & \\
\hline & & & Total & $\begin{array}{c}\text { As the } \\
\text { Primary } \\
\text { Activity }\end{array}$ & $\begin{array}{c}\text { Per } \\
\text { Home } \\
\text { Viewer }\end{array}$ & Mins & $\begin{array}{c}T V \\
\text { Percent }\end{array}$ & Mins & $\begin{array}{c}T V \\
\text { Percent }\end{array}$ \\
\hline ISA (Jackson) & 98 & 80 & 134 & 101 & 142 & 135 & 75 & 310 & 33 \\
\hline USA (44 cities) & 97 & 80 & 129 & 92 & 131 & 131 & 70 & 301 & 31 \\
\hline East Germany & 85 & 72 & 100 & 81 & 124 & 108 & 75 & 233 & 35 \\
\hline West Germany & 76 & 64 & 87 & 74 & 128 & 112 & 66 & 300 & 25 \\
\hline Belgium & 72 & 65 & 94 & 84 & 139 & 137 & 61 & 297 & 28 \\
\hline Czechoslovakia & 72 & 52 & 73 & 66 & 135 & 116 & 57 & 239 & 28 \\
\hline (100 dists) & 66 & 56 & 74 & 63 & 123 & 98 & 64 & 264 & 24 \\
\hline & & 65 & 96 & 58 & 107 & 91 & 64 & 245 & 24 \\
\hline & $\begin{array}{l}80 \\
59\end{array}$ & $\begin{array}{l}60 \\
60\end{array}$ & 82 & 70 & 130 & 120 & 58 & 262 & 27 \\
\hline & 54 & 47 & 63 & 54 & 125 & 87 & 62 & 309 & 17 \\
\hline & 52 & 40 & 45 & 42 & 109 & 116 & 36 & 249 & 17 \\
\hline slavia $(\mathrm{m})$ & 49 & 41 & 47 & 41 & 111 & 81 & 51 & 222 & 18 \\
\hline & 45 & 36 & 45 & 43 & 124 & 85 & 51 & 200 & 22 \\
\hline lavia $(\mathrm{k})$ & 35 & 35 & 48 & 37 & 127 & 87 & 43 & 311 & 12 \\
\hline & 26 & 17 & 17 & 16 & 95 & 79 & 20 & 231 & 7 \\
\hline
\end{tabular}

SOURCE: Adapted from J. P. Robinson, and P. E. Converse. 1972. The impact of television on mass media usages: A cross-national comparison
In A. Szalai (ed.). The Use of Time: Daily Activities of Urban and Suburban Populations in Twelve Countries. The Hague: Mouton and Co., pp. 197-212. An average child between the ages of 4
and 12 in Canada spends four hours of each day with television, that is nine years of his life by the age of 65 . T:levision influences eating, sleeping, coiversa-
tion, family interaction and social r.ovetion, family interaction and social move-
ment. In short, many aspects of moder life are influenced by the television medium by virtue of its impact on the use
of time and on social interaction. Televiof time and on social interaction. Televi-
sion has become a way of life in many sion participation - more akin to a musical
concert than to, for example, the rational process of reading the printed page.

The Viewer

Individual personal differences not-
withstanding audiences the world over go to the television set primarily to be entertained. They do not, generally speaking, go to be informed or challeng-
ed; they go to print for that. Research unfamiliar. As in the above analogies, the more regular and intense the participa
tion, the less the critical awareness. In a way, audiences treat television pro-
gramming as though it were a cliché of our everyday language. In a metaphorical same commercials again and again unt they become second nature through VOLUME 13, NUMBER 2, 198
RECOMMENDED USES OF

ey may not be able to recall the details shows and commercials, somehow
ey assimilate them along with the imlicit attitudes, beliefs and values proans and commercials are very familior but we pay little attention to them and have stopped trying to pry out their
meaning. We "become" the commercials meaning. We "become" the commercials an the sense that we unconsciously begin assuming their perception of our social and personal conditions. Attitudes
lowards women, sex , ethnic groups, children, religion, health, even smoking,
are a part of situation comedies and are a part of situation comedies and
dramas. Beliefs about life after death, democracy, capitalism, pollution, conservation, are in a variety of talk shows. Values relating to love, hate, tolerance,
cology, are in documentaries, dramas ecology, are in documentaries, dram
and news. The implicit messages can go noticed and as such have influenced us g before we know it.

The Viewing Context

The viewer, whether child or adult, is ggaged in a private, unthreatenin quiescence of home, in semi-darkness,
usually in a relaxed, often uncritical te. There is no need for human interaction or discussion of the program being however, when other things are going on. Children will play in the room for hours
for example, when there is a television texample, when there is a television
present and turned on (J.P. Robinson, 1972).

he nature of the television medium, its ith television, and the viewing context ads to a view of television as a dominan As health educators, we are faced with the realization that the television networks and stations exist and are there for us to use, and that audiences are attracted hat is imperceptibly changing beliefs an in relation to the beliefs, attitudes, intentons and behaviours already held by in ealth organizations to ensure that th ming reflect nonsmoking. Television hould be used in all aspects, not just hrough commercials and public servic ramming as well. Smokers must be lown that nonsmoking is a normative
ondition, that the alternatives to smoking are more desirable than smoking. onsmoking should not only be the norm in television, but should appear to be the
orm. What follows are a few recommentions or tips on how to use the medium support of continued nonsmokin following: that order adolescence; (Klein, 1979). (6) Use cheach. character does is more important than erve as an appealing and cogent model of

On the basis of the review of televiion's character, its strengths and formance of children and youth, the following tips are offered in support of
television's use in supporting nonelevision's use in supporting no
moking among children and youth.

(1) Use both public service spots $(15,30$ and 60 second) and programs (15, 30 and

(2) Repeat the public service spots as often as possible. repeat the programs as
often as well and repeat the nonsmoking theme in a frequent and constant fashion throughout the programs. (3) Tailor spots and programs for the specific audience in mind according to
age. For example, in the United States and Canada, audience research has found the

a) A pre-school child prefers cartoons, situation comedies and non-cartoon

(b) By the first or second grade, situation comedies dominate the list of preferred shows and their presence
as favourites remains substantially as favourites remains substantially
well into the beginning

(c) The end of elementary school years tends to mark a transition period when, in addition to the situation comedies and even some of the car-
toons favoured by younger childtoons favoured by younger child-
ren, action and adventure, music and variety, and various dramatic shows begin to come into favour;

(d) By the middle of the teens, "adult"
entertainment programming tends entertainment programming tends
to dominate the list of preferences man, 1972; Schramm, Lyle and
Parker, 1961).

(4) Programming and spots should be that audiences go to television to watch television rather than to watch specific
programs. Typically, they search the programs. Typically, they search the
various channesl until they find the program that is least objectionable and stay with that. In other words, audience tastes for entertainment demand that program-
ming be structured to entertain. Where there are competitive channels or competitive programming, audiences will taining or at least most unobjectionable

(5) Refrain from offering statistics, ex-
cessive information, and avoid using a cessive information, and avoid using

(6) Use characters and character types appeal for the target audience. What the
(7) Use both adult characters (models) is some evidence that youraters. There own age (Atkin, 1978).

(8) Audiences tend to trust sources similar to themselves that they directly dinary attributes are also effective as well s those with outstanding or heroic at

(9) Programs should show the beneficial nonsmoker.

the shouns shown should be as close the children's "reality" as possible (11) Situations that portray the nonsmoker as being rewarded

(the emothat appeal to rational and logical thought.

13) Avoid using fear tactics showing the health consequences of smoking. There is more effective to support work, and it more effective to support pro-social, moking (Atkin, 1978; Farquhar, et al. 977).

14) Programs and spots should be scheduled according to peak target audience viewing patterns. Programs vry strong chy strong competition on alternative
channels will not reach the critical audience.

15) Where possible in programs and 位, tie the imagery and messages, the trayed, to other elements of a comprehenive nonsmoking program that includes other schools, community and home. In
otherds, the television effort should not be an end in itself, but should be an stensible part of an overall comprehen-
ve program utilizing group and in-

\section{PRACTICAL EXAMPLES O}

LLEVISION USE

Organizations and funding bodies desirous of influencing smoking patterns youth must, of necessity, take the cost eneral approaches should be considered in the use of television. The first is to persuade the television industry to incorexisting program formats and schedules second is for the health organization. The preciate and learn from others of their ponsmoking emphasis into 
agency alone or in cooperation with other Health Organization-Sponsored agencies to develop programming and
promotional materials at cost and to buy space and time for their use as part of an approaches are expanded on briefly next.

Incorporative Programming Many countries have had good success in persuading the television industry to existing program formats. In Canada, the annual "National Non-Smoking Week" includes the carriage of non-smoking
messages, skits, films, presentations and messages, skits, films, presentations and
dramas in children's programs, in news, dramas in children's programs, in news,
in public affairs programs and in situation and variety programming that are regularly scheduled. This is accomplished by approaching program developers in
the television systems with ideas, materials, films and background evidence on the subject six months before the $\mathrm{Na}$ tional Non-Smoking Week is to be run
This allows program planners and television stations time to prepare for the support they are giving. Often, health
organizations or agencies have access to organizations or agencies have access to
well-known personalities, heroes, politiwell-known personalities, heroes, politi-
cians, actors, who are willing to donate time and efforts for the nonsmoking topic. In fact, health organizations often get the cooperation of well-known na-
tional figures more easily than do television stations or programmers. Wellknown sports figures and television stars
are more likely to donate their efforts to the Canadian Cancer Society, for example,than they are to the CBC or CTV networks that serve the country. Follow-up
visits and letters, phone calls and promovisits and letters, phone calls and promo-
tion to the television stations ensure tion to the television stations ensure
coverage prior to National Non-Smoking expressions of public appreciation are ofother health organizations for the support given by the media for National Nonbefore, during and after National NonSmoking Week on the subject of nonsmoking encourages parents to be mind-
ful of their influence on the smoking patterns of children.

The Great American Smoke-Outy sponsors The Great American Smoke-Out which follows similar patterns to National Non-
Smoking Week. The Great American
Smoke-O ceedings of the 4th World Conference on Smoking and Health entitled The Smok ing Epidemic. The American Cancer American movie stars and television personalities to give examples of the dramatic and glamorous identification $r$
nonsmoking. Most of this effort is nonsmoking. Most of this effort is
donated by the actors and time is given free by television networks and stations. works and local stations. The ads were aimed at persuading young people and
adults to stop smoking or to persuade A number of studies have been con-
ducted in several countries that include television in smoking control programs. youth as target audiences. A good deal of he research is based on the assumption that a single intervention through televibehavioural change. Thus, whed the chavioural change. Thus, when the
evidence indicates little significant change in behaviour, it misses an opportunity to demonstrate the sense in which
attitudes and beliefs or general perceptions are influenced by the intervention.
In the United Kingdom, M. Jefferys in 1962 conducted a project through BBC The twenty-five-minute program produced in a "Spotlight" series was broad-
cast to schools. Its effects were assessed cast to schools. Its effects were assessed
using pre-test, post-test evaluation using pre-test, post-test evaluation
designs with a matched control group. Six were used in the experiment. The twentyfive-minute program was in the format of doctor talking and using graphs, diagrams and a healthy and a cancerous moking and death and illness. Extracts from films helped to illustrate how experimental work points to various adverse effects of smoking. At the end, the doctor showed how advertisers enagers were interviewed with the resulting messages of how most young people begin to smoke and how they attempt to f smoking was stressed and alternative ways to spend money were suggested. A prominent sportsman, television per-
sonality and the doctor talked about their reasons for not smoking. Little difference in the smoking patterns of young people in the experimental and control groups proportion of young people in the ex-
porting proportion of young people in the exsocial and health point of view than those in the control group (Jeffreys, 1963). O'Keefe conducted a study in the between attitudes and smoking behaviour tilizizing the anti-smoking campaign healthed on television by the various
orgations in the late $1960^{\prime} s$ The investigation was carried out in surrounding cities. The sample was
broken down into those people under and 21 years of age, and questionaire nd telephone surveys were used to the study, 80 to 100 commercials were shown each week. These commercials
were produced by the health organizations but were carried free on the net- laces of work, organization and involvevices in support of the program; trainin of personnel including teachers, volun-
eer workers, community leaders; utilileer workers, community leaders; utili-
zation of environmental services such as nonsmoking restrictions and laws. The community program effectively reduced he levels of the three risk factors in the population. Approximately $7 \%$ of the adult population and $10 \%$ of the smokers watched some or all of the 45 -minute
elevision shows. Of the smokers, $20 \%$ gave up smoking and roughly $10 \%$, or
some 10,000 people, were still nonsmokers after six months or more. Among the viewers who took part in some 100
self-help groups that had formed in North self-help groups that had formed in North
Karelia, the cessation rate was roughly wice as large $-20 \%$ after six months.
twath The Stanford Heart Prevention program conducted through Stanford University in
the U.S.A. utilized similar methods to engage entire communities in support of media, group activity and individualized results. Three years after the program started, the proportion of smokers had decreased by $3 \%$ in the control community, by $8 \%$ in the media-only community,
and by $24 \%$ in the media-plus-counselling communities. Fifty percent of the highrisk smokers received face-to-face coun-

had quit.

In Canada, a large-scale nonsmoking
program called "Time to Ouit" was program called "Time to Quit" was
developed and tested by the Canadian Cancer Society and Health and Welfare Canada in 1982 to engage large populations in three half-hour television shows,
full community-level publicity and support, and self-help smoking cessation
material. These, and other projects like material. These, and other projects like
them, are special intensive programs
from which we can all learn in developing our nonsmoking programs.
In the United Kingdom, the BBC is aired six 10-minute television programs
on nonsmoking during January, 1982 . series was presented by Dr. Miriam Stop pard, who is known for her practical approach to health problems. Three people were followed over six weeks as they
made the decision and deal with the difficulties and experience the benefits of
stopping smoking. The program also stopping smoking. The program also
featured advice from specialists in the smoking cessation field, success stories from well-known personalities, some humour, and hints and tips from some of the many millions of ordinary people who
have successfully stopped smoking. The above examples are by no means
The exhaustive, but give some indication of sume of the successful and some not-so-
successful approaches taken to use televsion in a program to support nonsmoking.
Several articles are mentioned at the end of this section which more fully review sion and other mass media in the health

One final note here. In most countries on Adolescent Behaviour and Health, VOLUME 13, NUMBER 2,198 which example can be taken. there is no tobacco advertising on televi-
sion. In those countries where tobacco continues to be advertised on television measures should be taken immediately to eliminate that advertising. The modellin influence on young people is considerable through television, and promotion of tobacco companies promote sports and cultural events which receive coverage on television. This also undoubtedly influences the perceptions of young people duct itself. Measures should be taken in every country to restrict promotions of limination of tobacco advertising from elevision but fly in the face of the spirit the desire to remove promotion of

The imagry and messages promoting smoking. This should be true of its advertising programming, its news and its current

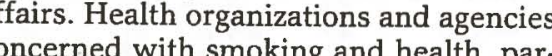
ticularly in relation to youth, have a sponsibility to persuade television net作 worther, as has been argued bove, health organizations and agencies rammers to include nonsmoking im messages in all forms of rograms and to carry public service an-
nouncements and public service proamming.

\section{BIBLIOGRAPHY}

Mediated Health Communication Compaigns" A paper presented at the NaBall, S.J., and G.A. Bogatz. The First Year of Sesame Street: An Evaluation. Princeton: Educational Testing

Sandura, A. "Analysis of modelling proPsychological A. Bandura (ed.)
Modelling: Conflicting Theories. Chicago: AldineAtherton, 1971, pp. 1-62.
Bandura, A. "Social-learning theory of identificatory processes." In D.A. tion Theory and Research. Chicago: Rand McNally, 1969, pp. 213-262.

McNutt
TOWARDS A WHOLLY OBJECTIVE Michaychuk and Yakulic
IMPACT OF A LOGO PROGRAM ON
NATIVE ADULTS Soudak and Karan

FORMATIVE RESEARCH ON TELIDON

Barron
CHILDREN'S MEDIA

Braun and Kolomeychuk
THE ART OF TELEVISION

Laucht
MICROCOMPUTER
CONSIDERATIONS

ACQUISTTION

Shears
EDUCATIONAL COMMUNICATIONS
PERSONNEL: THE NEW INTERNA-

Bates PROCESS

Duncan
PREPARING PERSONNEL FOR VICE POSITIONS: SOME OBSERVA-

Wyman
SLOW ROAD TO INTERNATIONAL AV

Ghauremani, et. al.
AN ANALYSIS OF THE COMPUTER RELATED CURRICULUM IN THE GRAM AT CONCORDIA

Palmer and Tesarowksi
STONY MOUNTAIN

DISTANCE

Bennett

RESULTS OF A STUDY TO IDENTIFY UTILIZATION LEVELS BY CANADIN

Lacy SKIES, GREY CLOUDS, OR

BLUE SKIES, GREY CLOUDS, OR
FALSE DAWN: EDUCATIONAL APPLISATELLITES AND THE PROSPECTS FOR DISTANCE EDUCATION IN
AUSTRALIA odfreyson

tion of imitative responses." Journal of Personality and Social Psychology, Bandura, A., D. Ross, and S.A. Ross. learning." Journal of Abnormal and Social Psychology, 67, 1963, 601-7. cent Aggression. New York: Ronald, Baumrind, D. "Socialization and in-
strumental competence in young forcement contingencies on the acquisi- 
children." In W.W. Hartup (ed.), The
Young Child: Reviews of Research. Washington, D.C.: National Association for the Education of Young Children vol. 2, 1972, pp. 202-224.

Becker, L.B., M.E. McCombs, and J.M McLeod. "The development of political cognitions." In S.H. Chaffee (ed.), and Strategies for Research. Vol. 4 of Sage Annual Reviews of Communica-
tion Research, Beverly Hills, California: Berkowitz, L. "Violence in the mass media. Aggressalysis. A Social McGraw-Hill, 1962b, pp. 229-255.

Berkowitz, L. "Some aspects of observed agression." "Journal of Personality and Social Psyc Berkowitz, L., and E. Rawlings. "Effects of film violence on inhibitions against
subsequent aggression." Journal of Abnormal and Social Psychology

E. Hewitt. Mass Medi Education and Alcohol: A State-of ty of Pittsburgh, 1977.

Blumler, J.G., and J.M. McLeod. "Communication and voter turnout in $\mathrm{Br}-$ theory and survey res.), Sociological Sage Publications, 1974, pp. 265-312. Brown, R. Social Psychology. New York: Free Press, 1965.

Collins, W.A., T.J. Berndt, and V.L. Hess "Observation leaning of motives and A development lovitud "Child Development. 45, 1974, 799-802. Comstock, G., S. Chaffee, N. Katzman $M$. McCombs, and D. Roberts. Televi
sion and Human Behaviour. New sion and Human Behaviour. New
York: Columbia University Press, 1978. Corder-Bolz, C., and "S. ORR ryan. 28, 1978, 97-103.

Dominick, J.R., and B.S. Greenberg. "Attitudes toward violence: The in teraction of television, exposure, family Comstock and E.A. Rubinstein (eds.) Television and Social Behaviou Vol. 3, Television and Adolescen Aggressiveness. Washington, D.C. Government Printing Office, 1972, pp

of Sharing: R. Vasta. "The Modelin vicarious reinforcement, symbolization, age and generalization." Journal of Experimental Child Psychoiogy,

arquhar, J.W., N. Maccoby, P.D. Worrid,
J.K. Alexander, H. Breitrose B.W. Brown, Jr., W.L. Haskel, A.L. McAlis ter, F.J. Meyer, J.D. Nash, and M.P. Stern. "Community education for ca- diovascular health." Lancet. 4, June filmed violence." In J.P. Murray E.A. Rubinstein, and G.A. Comstock (eds. Television and Social Behavior. Vo , Television and Social Learning. . Fishbein, M., and I. Ajzen. Belief, Attitude, Intention and Behaviour. Reading, Mass.. Addison-Wesley, 1975. imitative behaviour." Bulletin 69, 1968, 316-337. Gerbner, G., and L. Gross. "Living with television: The violence profile." Journal of Communication. 26(2), 1976,

Gerson, W.M. "Mass media socialization Social Forces. 45, 1966, 40-50

Green, P. "The Mass Media Anti-Smok ing Campaign on Smoking and Health. Proceedings of the Third World Conference on Smoking and Health Taylor (eds, Vol II, US, Depall, of Health, Education and Welfare, 1971, pp. 245-254.

Greenberg, B.S. "Gratifications of televi sion viewing and their correlates for Katzh children." In J. Blumer and $\mathbb{B}$ municatons: Current Perspektives on Gratifications Research. Sage Annual Reviews of Communicatio Research, Vol. 3. Beverly Hills, Ca. Sage, 1974, pp. 71-92

. violence: A replication." In G.A. Con stock, E.A. Rubinstein, and J.P. Murra (eds), Television and Socia Behaviour. Vol. 5, Television's E fects: Further Explorations. ing Office, 1972 pp. 211-230. Griffiths, G. "The Educational Approach to Health Work." The Health Education Journal, Vol XV, No. 1., March,

films, D.J. "Imitation and retention of models." Journal of Personality and Social Psychology. 2, 1965, 97-100. Jefferys, M. "Smoking amongst school
children." The Medical Officer. 109 , $1963,91-93$.
. tion of Social Psychology. New York Wiley, 1967. The Effects of Mass
Klapper, J.T. The Communicaton. New York: Fre Press, 1960.
Klein, P.

Morgenstern (ed. Inside the Business. New York: Sterling Publish-

Kraus, S., and D. Davis, The Effect of
Mass Communication on Political vania State University Press, 1976 Lau, R., R. Kane, S. Berry, J. Ware, and D Ray. "Channeling Health: A Review o the Evaluation of Televised Health Rand Paper Series, 1978.

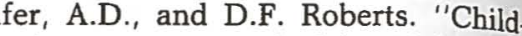
In J.P. Murray, E.A. Rubinstein and G.A. Comstock (eds.), Television and ach D.C.: Government Printing 1972, pp. 43-180.

Ile, J, and H.R. Hoffman. "Explorations reschorn of television viewing by Rubinstein, G.A. Comstock, and J.P. Mehaviour. Vol. 4, Television in o-Day Life: Patterns of Use. Washington, D.C.: Government Prin ing Office, 1972 , pp. 129-256.

and ing." Child Develop for social lear239-252.

Maccoby, E., and C.N. Jacklin. The Pex 197 political campaigns: Information Kline and P.J. Tichenor (eds.), Curren
Klicion, and persuasion." In F.G Perspectives in Mass Communic 1972, pp. 169-194.

urray, J.P. "Television in inner-city boys." In E.A. Rubinstein, G.A. Comstock, and J.P. Murray (eds.), Telev Television in Day-to-Day . Vol. 4, Telen ment Printing Office, 1972, pp Keefe, M.T. "The anti-smoking com mercials: A study of television's impact Quarterly. 35, 1971, 242-248. Quarterly. 35, 1971, 242-248.
Peterson, R.C., and L.L. Thurstone. Motion Pictures and the Socia Attitudes of C
Macmillan, 1933 .

Porter, F. "Assessing public reaction to an anti-smoking campaign." Ontario Pasad, V., T. Rao, and A. Sheickh. "Mother vs. Commercial." AVCR. Vo $28,1978,91-97$

Suska, P., J. Tuomilehto, J. Salomen, L. Neittaanmaki, J. Maki, J. Virtamo, "Changes in coronary risk factors dur
"Cissing ing comprehensive five-year community program to control cardiovasculat.
disease [North Karelia Project).
Britisn Medical Journal. November Dedical Jou children: A developmental approach." In I. de Sola Pool and W. Schramm (eds.), Chandbook of Communica-
tion. Chicago: Rand McNally, 1973, pp. 174-215.
Roberts, D.F. "The nature of human communication effects." In W. Schramm and D.F. Roberts (eds.l, The Process (rev. ed.). University of Illinois Press, 1971, pp. 347-387. Life Violence: What the Research
Life Says." A working paper for the Motion Picture Research, Stanford University, 1968. schramm, W., J. Lyle, and E.B. Parker.
Television in the Lives of Our

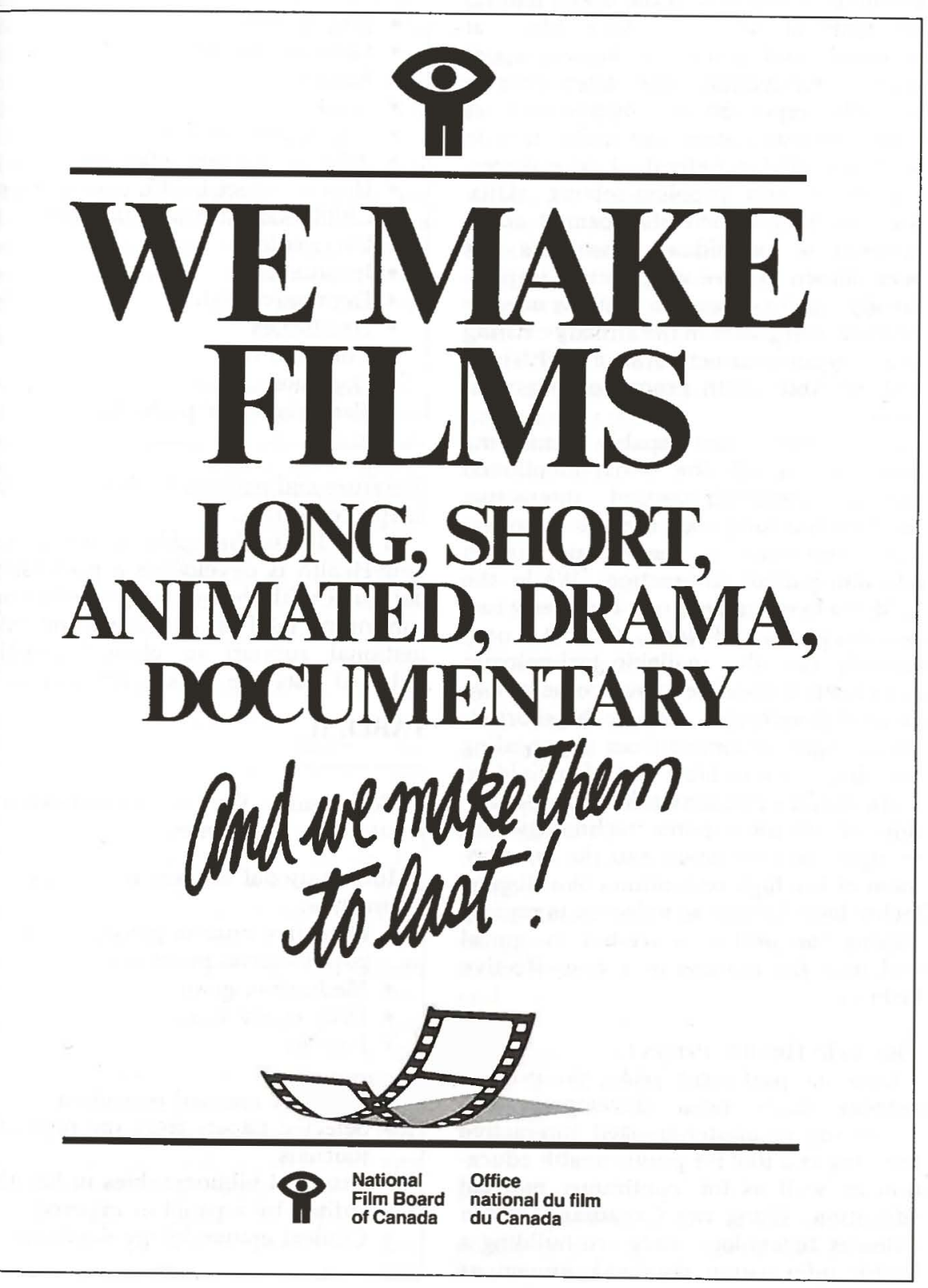

CANADIAN JOURNAL OF EDUCATIONAL COMMUNICATION
Children. Stanford, behaviour." In J.P. Murray, E.A. Rubinstein, and G.A. Comstock (eds.) 2. Television and Social Learning. Washington, D.C.: Government Printing Office, 1972, pp. 202-317. Smoking." The Sming the Onset of Edited by Lars M. Ramstrom. Stockholm : Almquist and Wiksell International, 1979, pp. 166-173.

ken. A Manual on Smoking and Children. UICC Technical Report Series, V3, Geneva, 1982

R.B. "Some effects of the 'space' rials." Public Opinion Quarterly, 18, 1954, 367-374. sion content and young children's

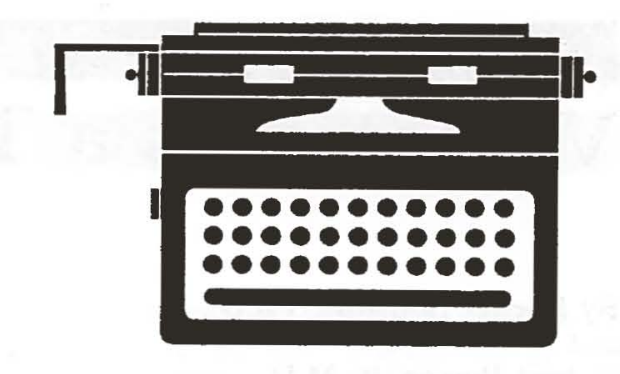

\section{LETTERS TO THE EDITOR}

EMERGENCY LIBRARIAN is Canada' libraries; at the present timen for schoo proximately 3,500 subscribers. We are journal. We exchange publications with large number of similar journals in Canada, the United States, and other
countries. We would be interested in exchanging publications with CJEC. ..And, in my position with the Van-
couver School Board, I would like to concouver School Board, I would like to congratulate you on the incredible develop "must read" journal in the last few years. I congratulate you!

Co-editor, EMERGENCY LIBRARIAN

Your journal, Canadian Journal of
Educational Communication is within the cope of the ERIC Clearinghouse on Information resources... We examine new decision CIJE list. We will index and annotate articles from the first volume and subsequent issues. . We appreciate your con sideration of our request. Director of Acquisitions ERIC

I have just finished reading the January issue of CJEC and am very impressed articles. You are doing an excellent job, Denis. June Landsburg Co-ordinator,
Knowledge Network Projects

Thank you for sending me the two issues of the CJEC ... (MY) article looks the fine job you have done in putting together this unorthodox article. Nikos Metallinos Assoc. prof. of Communication Studies Concordia University
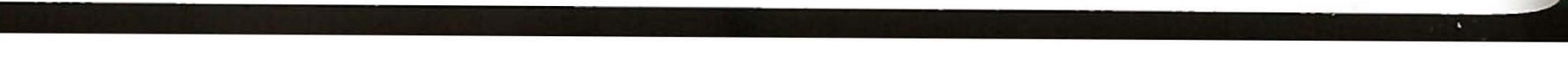